\title{
Rut wat Boas se 'voete' oopgemaak en by hom gaan lê het: Die betekenis van hierdie simboliese aksie in Rut 3:7 in die lig van Eksodus 4:25
}

\begin{abstract}
Authors:
Philip Venter ${ }^{1}$

Wynand Minnaar ${ }^{2}$

Affiliations:

${ }^{1}$ Department of New

Testament and Exegesis, University of Pretoria,

South Africa

${ }^{2}$ Skool vir Bybelwetenskappe en antieke tale, North-West University, South Africa

\section{Correspondence to:}

Wynand Minnaar

Email:

wfminnaar@gmail.com

Postal address:

Posbus 160, Hoedspruit

1380, South Africa

Dates:

Received: 25 June 2012

Accepted: 02 Feb. 2013

Published: 29 May 2013

How to cite this article: Venter, P. \& Minnaar, W. 2013, 'Rut wat Boas se "voete" oopgemaak en by hom gaan lê het: Die betekenis van hierdie simboliese aksie in Rut 3:7 in die lig van Eksodus 4:25', Verbum et Ecclesia 34(1), Art. \#757, 4 pages. http://dx.doi. org/10.4102/ve.v34i1.757
\end{abstract}

\section{Copyright:}

(C) 2013. The Authors.

Licensee: AOSIS

OpenJournals. This work

is licensed under the

Creative Commons

Attribution License.
Read online:

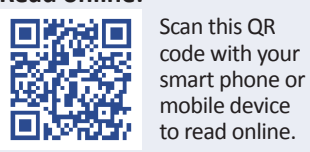

Ruth who uncovered Boaz's 'feet' and had laid there with him: The significance of this symbolic act in Ruth 3:7 in the light of Exodus 4:25. This article investigates the possibility that Ruth 3:7, where Ruth went to lie at Boaz' 'feet', can be read in an intertextual way in the context of Exodus 4:25. In Exodus 4:24-26, whilst at a camping place on their way to Egypt, the Lord came to kill Moses. Then Zipporah, his wife, took a sharp stone (or stone knife), cut off the foreskin of her son and touched Moses' 'feet' with it. Because of the circumcision she said to Moses: 'You are a bridegroom of blood to me'. And so the Lord spared the life of Moses. Zipporah took the initiative and because of this, God's will and plan for Moses could still be reached. The covenant duty of circumcision, according to Genesis 17:10-14, could also be accomplished through her intervention. This section also clearly illustrates that God welcomes non-Israelites to enter into the community of Israel. In Ruth 3:7, the same word for feet is used as in Exodus 4:25, namely .רגל The analogous use of this word clearly emphasises the importance of the functioning of the covenant of God with Israel. There are also other similarities between these verses of Scripture. It is indicated that Ruth, like Zipporah, also took the initiative and intervened to ensure that God's covenant plan for Israel will be accomplished. It is also indicated that Ruth, like Zipporah, is accepted into the community of Israel and that she will play an important role ensuring the future of the offspring of Mahlon/Boaz.

\section{Inleiding: Intertekstuele eksegese van die Ou Testament}

Die intertekstuele eksegese van die Ou Testament (OT) gaan van die standpunt uit dat die betekenis van spesifieke tekste nie op 'n diskresionêre, aparte en opsigselfstaande manier afgelei kan word nie. Hiervolgens word gereken dat tekste saamgestel is uit 'n mosaïek van aanhalings en dat ' $n$ enkele teks verteenwoordigend kan wees van verskeie betekenisvolle sisteme (Beal 1992:22-23, 2000:128-130). Die bruikbaarheid van hierdie benadering is veral geleë in die teoretiese basis wat dit verskaf om ooreenkomste tussen verskillende tekste te verklaar. Dit is veral van toepassing op tekstuele ooreenkomste wat enersyds nie geredelik as geleen beskryf kan word nie, maar andersyds ook nie as blote toeval beskou kan word nie (Nikaido 2001:220; vgl. Roop 2002:22). Esses (1977:26) beskryf bogenoemde aspek soos volg: 'This intricate inter-contextual message is spread throughout the Old Testament. Sometimes the line is perceived to be broken, and an apparently unrelated passage fills in the missing dot'. Die tekste hier ter sprake is veral die geskrifte wat gedurende die einde van die voor-eksiliese, die eksiliese en die na-eksiliese tye onstaan het (Sommer 2004:1829, 1835). ${ }^{1}$

Wat die boek Rut betref, is een van die vernaamste huidige tendense om die geskrif op 'n intertekstuele manier te eksegetiseer (kyk bv. Braulik 1999:1-19; Fischer 1999:107-112; LaCocque 2004:1-6; Nielsen 1997:8-12, 29-33; Zenger [1995] 2004:224-225). In die lig hiervan kan daar gelet word op LaCocque (2004:2) wat na Rut verwys as 'n 'socio-legal commentary' op die Tora of Pentateug). Zenger ([1995] 2004:224-225) beskou die boek weer as 'n 'halachischen Midrasch'([1995] 2004:225), in die sin dat die boek die Tora op 'n nuwe manier interpreteer en aktualiseer. Nielsen (1997:7-8) wys verder daarop dat die boek Rut sterk aansluit by die patriargale literatuur en beskryf die boek selfs as een van die 'patriarchal narratives' (1997:7). Rut word dus in hierdie sin geïnterpreteer as 'n geskrif wat teen die agtergrond van die Pentateug verstaan moet word en dat die geskrif die geskiedenis van die aardsvaders, wat in die Pentateug opgeteken is, opnuut interpreteer en aktualiseer.

Die gebeure in Eksodus 4:25 waar Sippora die voorhuid van haar seun teen die 'voete' van Moses gedruk het, kan dus bydra tot die verstaan van wat gebeur het in Rut 3:7 toe Rut Boas se 'voete' oopgemaak en by hom gaan lê het. Hiervolgens kan Rut 3:7 gesien word as 'n interpretasie en aktualisering van die gebeure wat in Eksodus 4:25 opgeteken is.

1.Wat die datering van die boek Rut betref, is daar redelike konsensus onder geleerdes dat die geskrif na-eksilies gedateer moet word (vgl. bv. Brueggemann 2003:320; Bush 1996:18-30; LaCocque 2004:18-21; Matthews 2004:209; Pressler 2002:262; Spangenberg 2000:190; Zenger 1986:25-28, [1995] 2004:225-227; Zevit 2005:574-575). 


\section{Eksodus 4:25}

Eksodus 4:25 word voorafgegaan deur die beskrywing van Moses wat sy skoonpa, Jetro, versoek dat hy teruggaan na sy familie in Egipte toe. Nadat Jetro hom sy toestemming gegee het, het Moses met sy vrou en seuns die tog na Egipte aangepak (4:18-23). In Eksodus 4:24-26 lees ons dat terwyl Moses en sy gesin op pad oornag het, die Here na hom gekom het om hom dood te maak. ${ }^{2}$ Moses se vrou, Sippora, neem toe 'n skerp klip of klipmes en sny haar seun se voorhuid af.

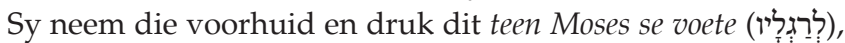
waarop sy in verwysing na die besnydenis verklaar dat Moses haar bloed-bruidegom is. Hierop het die Here Moses met rus gelaat.

Alhoewel die rede vir die Here se aggressie teenoor Moses nie heeltemal duidelik is nie (kyk Childs [1974] 2004:95-96, 101; vgl. Tigay 2004:113), kan vanuit die teksverband afgelei word dat Moses se nalatigheid om een van sy seuns (vlgs 18:4, Eliëser) te laat besny deur die Here gereken is as sonde wat met die dood strafbaar is (Willis 2010:179). Deur Sippora se ingrype in die situasie word dié verbondsverpligting van die besnydenis - volgens Genesis 17:10-14-egter steeds nagekom (Stuart 2006:155-156). Deur die bebloede voorhuid van haar seun het Sippora Moses van die dood gered en hom op 'n besondere manier aan haar verbind. Benewens dat hy haar eggenoot is, noem sy hom haar 'bloed-bruidegom' (חָתַתן דָדמִִים). Hierdie aksie van Sippora is verder soortgelyk aan die bring van 'n rituele offer aan die Here. Dit is ook uniek aangesien daar op geen ander plek in die Ou Testament beskryf word dat 'n vrou so 'n offer bring nie (O'Donnell Setel [1992] 1998:33, 35; vgl. Stuart 2006:154).

Binne die konteks van die verbondsverhouding van die Here met Israel speel die besnydenis 'n wesenlike rol (kyk Gen 17:10-14). Dit is daarom betekenisvol dat Sippora die bebloede voorhuid van haar seun teen die 'voete' van Moses

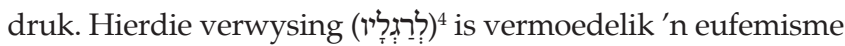

2.Die Hebreeuse teks dui in 4:24 net aan dat die Here "hom wou doodmaak' (הָמִיתו)

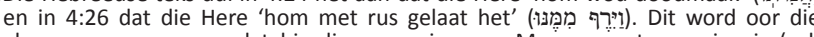
algemeen aangeneem dat hierdie verwysings op Moses van toepassing is (vgl. bv. die vertalings in die NAB en NLV). Die rede hiervoor is vernaamlik omdat die gedeelte geïnterpreteer word as Moses wat gesondig het in die oë van die Here deur sy seun nie te laat besny nie en amper met sy lewe hiervoor moes boet (Willis 2010:179; vgl. Childs [1974] 2004:96, 101; Gowan 1994:37). Childs ([1974] 2004:98, 103) toon verder aan dat die spesifieke verwysing na Moses se seun in 4:25, indien die bg. verwysings in 4:24 en 4:26 op hom (Moses se seun) van toepassing was, nie nodig sou gewees het nie. Daar is egter ook geleerdes wat van mening is dat hierdie nodig sou gewees het nie. Daar is egter ook geleerdes wat van mening is dat hierdie verwysings op Moses se seun van toepassing is, byvoorbeeld Stuart (2006:152-153, 155-156) wat meen dat die gedeelte in ooreenstemming met 4:23 binne die grote konteks van die sterfte van die eersgebore Egiptiese seuns gesien moet word. Die ( se eersgebore seun. In hierdie artikel word daar aangesluit by die interpretasie da die verwysings op Moses van toepassing is

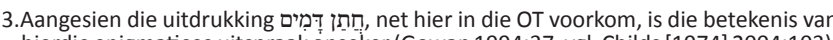
hierdie enigmatiese uitspraak onseker (Gowan 1994:37; vgl. Childs [1974] 2004:103). Tigay (2004:113-114) toon aan dat die uitdrukking in Akkadies en Arabies in die konteks van 'beskerming' gebruik word en in Arabies ook op 'besnydenis' kan dui.

4.Benewens dat רגל as reël na 'n mens se 'voet' verwys, kan die woord ook na die geslagsdeel van 'n man verwys; dit kan egter ook verwys na sy bene van die heupe af, of dit kan'n beskrywing wees van die omgewing naby die voete (Vance 2003:55). Aangesien die voet(e) van' $n$ mens die laagste deel van sy of haar liggaam is, is dit onvermydelik dat die liggaamsdeel in aanraking kom met vuilheid - die onrein omgewing waarin geleef word. Dit is ook as gevolg hiervan (volgens Stendebach omgewing waarin geleef word. Dit is ook as gevolg hiervan (volgens Stendebach
2004:315, die 'zone of uncleanness') dat רגל soms as eufemisme vir geslagsdeel 2004:315, die 'zone of uncleanness') dat רג' soms as eufemisme vir geslagsdee
gebruik word (Eks 4:25; Jes 7:20). Die OT verwys in hierdie konteks byvoorbeeld eufemisties na 'om te urineer' as מִימֵי רַגליהם 'hulle voet water' (2 Kon 18:27; Jes

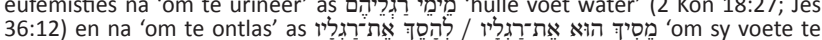

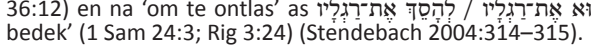

wat verwys na die 'geslagsdeel'5 van Moses. Sippora het dus waarskynlik die bebloede voorhuid van haar seun teen die liggaamsdeel van Moses gedruk wat as 'n teken gedien het van die verbond tussen die Here en Israel (vgl. Childs [1974] 2004:96, 101, 103-104; Stuart 2006:154-155; Tigay 2004:113).

Dit is verder duidelik dat Sippora in die gedeelte beskryf word as die een wat inisiatief neem om die krisissituasie op te los. Deur haar tussenkoms is Moses gered en kon God se wil in die heilsgeskiedenis van Israel geskied (Stuart 2006:155-156; vgl. Childs [1974] 2004:103-104; O'Donnell Setel [1992] 1998:33, 35). Die gebeure beskryf verder dat 'n vreemde vrou (van heidense Midianitiese oorsprong) ook opgeneem kan word in die gemeenskap van Israel. Willis (2010:178) beskryf dit soos volg: 'Thus, the present order of the text indicates a foreign woman and her son were fully qualified to enter Israel ...'

\section{Rut 3:7}

Rut 3:7 word voorafgegaan deur die beskrywing van die plan van Naomi om vir Rut 'n rusplek te vind sodat sy versorg kan wees (3:1-5). Die twee vrouens was in 'n uiterse benarde situasie aangesien die oes verby was (met die tydelike uitkoms wat dit gebring het) en daar nog nie 'n permanente oplossing vir hulle (veral Rut se) krisissituasie gekom het nie (Hubbard 1988:24; vgl. Blotz 2005:47; Sakenfeld 2002:164-178). Dit noop Rut om, na aanleiding van Naomi se plan, die inisiatief te neem en na Boas op die dorsvloer te gaan met die spesifieke versoek dat hy haar onder sy beskerming neem (Pressler 2002:284; vgl. Matthews 2004:233; Roop 2002:59). Die motivering vir Naomi se plan kan onderskei word in haar retoriese vraag aan Rut in 3:2 waar sy dit onder woorde bring dat Boas 'n familielid van hulle is (Prinsloo 1982:61-62; vgl. LaCocque 2004:89-90). Hierdie verwysing het volgens Steinhoff (1995:291) tot gevolg dat Rut later (in 3:9) by Boas aanspraak kan maak op die familieverpligtinge van lossing en die leviraatshuwelik.

In gehoorsaamheid aan haar skoonma se plan het Rut nougeset gedoen wat Naomi aan haar gesê het om te doen. Sy het nadat Boas die aand gaan slaap het, sy 'voete/geslagsdeel' oopgemaak en gaan lê. Soos in die geval van Eksodus 4:25

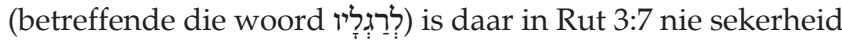

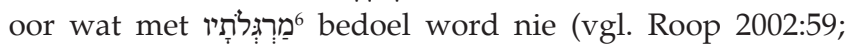
Loader 1994:61). Indien hierdie gedeelte teen die agtergrond van Eksodus 4:24-26 geïnterpreteer word, kan die spesifieke verbondbetekenis nie misgekyk word nie. Soos Sippora se handeling die verbond - en die eise van die verbond (spesifiek Gen 17:10-14) - tussen die Here en Israel bevestig het, kan Rut se handeling daarop dui dat sy, in ooreenstemming met Sippora se optrede, met die liggaamsdeel van Boas identifiseer wat volgens Eksodus 4:25 spesifiek aan die verbond verbind word. Rut dui dus hiermee aan dat dit haar wens is dat haar verhouding met Boas sal geskied binne die

5.Vergelyk die vertaling van $4: 25$ in die NLV: '... Sy het dit teen Moses se geslagsdeel gedruk ...'

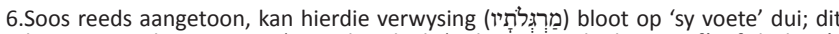
kan egter ook verwys na 'sy geslagsdeel, 'sy bene van die heupe af', of dit kan 'n beskrywing wees van die 'omgewing naby sy voete' (Vance 2003:55). 
eise $^{7}$ van die verbondverhouding van die Here met Israel. Hierdie aanname word bevestig deur haar versoek aan Boas in 3:9, naamlik dat hy sy vleuel oor haar uitbrei. Rut wat aan Boas vra om haar met sy vleuel (כְנָספָּ) te bedek, vra eintlik vir hom om die punt van sy kleed oor haar uit te sprei (Krüger 1984:83-85, 2004:344). Die kleed wat Joodse mans gedra het, het spesifieke godsdienstige betekenis gehad, aangesien dit gedien het as verbondsimbool vir iemand wat in ooreenstemming met die Mosaïese wette leef. Hiervolgens moes daar aan die vier punte van die kledingstuk se soom klossies aangebring word. Die klossies, in ooreenstemming met Numeri 15:37-41, het gedien as konstante herinnering aan die wette van Moses (Dommershausen 1993:229-231).

Dit is verder duidelik dat Rut, soos Sippora, ook die inisiatief neem in die handelinge ${ }^{8}$ wat op die ou end tot die voortbestaan van 'n Judese familie van nasionale belang lei. Nielsen (1997:76-77; vgl. LaCocque 2004:138-139; Lawrie 1999:96) sluit hierby aan deur daarop te wys dat die ontmoeting tussen Boas en Rut in essensie gesien kan word as twee mense wat verantwoordelikheid aanvaar vir die voortbestaan van 'n familie, en sy beskryf dit soos volg: 'It is a question of the continued survival of the family - and Ruth's role as part of that family' (1997:76). Sippora se inisiatief en optrede lei tot die oorlewing van Moses en die voortbestaan van sy nageslag. Rut neem inisiatief en haar optrede lei tot die voortbestaan van die nageslag van Maglon/Boas. ${ }^{9}$ In die geval van Sippora het Moses die volk van die Here uit Egiptiese slawerny verlos, en in die geval van Rut is koning Dawid, die grootste en roemrykste van al die konings van Israel, uit die nageslag van Maglon/Boas gebore.

Steinhoff (1995:291) toon aan dat die gebeure op die dorsvloer vernaamlik geïnterpreteer moet word teen die agtergrond van Rut, die Moabiet, wat as gevolg van haar huwelik met Boas in die gemeenskap van Israel geïntegreer word. Haar optrede kan hiervolgens verstaan word as huweliksaansoek (vgl. Prinsloo 1982:64-65) teen die agtergrond van haar verbonduitspraak in 1:16: ' $\mathrm{u}$ volk is my volk, en $\mathrm{u}$ God is my God'. Rut, die 'vreemdeling', ${ }^{10}$ die 'Moabitiese vrou' (1:4, 22; $2: 2,6,21 ; 4: 5,10)$, word dus opgeneem in die gemeenskap

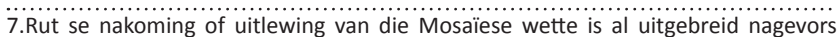
Kortliks kom dit daarop neer dat die boek Rut aantoon dat Rut se selfopofferende optrede, wat veral neerslag vind in haar uitlewing van חסד jeens haar skoonma (Kaiser 1992:152; Linafelt 1999:11; Zenger [1995] 2004:225), gesien kan word as navolgenswaardige voorbeeld vir Israel (Hamlin 1996:16, 78; LaCocque 2004:1-6; Loader 1986:103; 2004:694). Hubbard (1988:65-66, 72-74) wys byvoorbeeld hierop as die 'ideal lifestyle' (1988:72) vir Israel, en Allen, Hartley en McKenn ([1982] 1996.525) beskryf die lewenswyse van 70 ח as die 'covenant ideal, the lifestyle of hesed or "loyalty". In essence, to do hesed is voluntary to "go beyond the call of duty"'

8.Beide die vrouens se optrede is buitengewoon: In die geval van Sippora is haar optrede soortgelyk aan die bring van 'n rituele offer aan die Here, wat uniek is in die OT (O'Donnell Setel [1992] 1998:33, 35; vgl. Stuart 2006:154). In die geval van Rut tree sy op 'n wyse op wat Matthews (2004:233; vgl. Pressler 2002:284; Roop 2002:59) beskryf as 'a cultural and spatial transgression'. Hy beskryf egter die noodsaak van Rut en Naomi se optrede soos volg: 'However, given their situation, they have little choice but to violate the social and physical boundaries set by thei society' (2004:233)

9.Die rede waarom beide Maglon en Boas genoem word, is die volgende: In 4:10 word die kind wat gebore sou word - in lyn met die leviraatshuwelik - beskou as dié van Maglon. In 4:12 word die bede egter uitgespreek dat Boas as gevolg van sy huwelik met Rut, 'n nageslag sal hê soos dié van Peres (vgl. Campbell 1975:172; LaCocque 2004:148-149; Loader 2004:688-689).

10. Rut se vreemdelingskap word in 2:10 beklemtoon deur die gebruik van die woord נָכְרִיה (vgl. Esra 10:2, 10,11, 14, 17, 18, 44; Neh 13:27), in plaas van die meer algemene term נגר wat gedurende die na-eksiliese tydperk' $n$ tegniese term was waarmee' $n$ bekeerling tot Judaïsme aangedui is (LaCocque 2004:22-23, 70). van Israel (Hubbard 1988:67-68; vgl. Prinsloo 1982:107; Thomas 2002:155-169; Zenger 1986:116-117). ${ }^{11}$ Soos in die geval van Sippora is die genade van die Here nie net tot sy uitverkore verbondsvolk beperk nie, maar word heidene ook in sy raadsplan ingesluit. ${ }^{12}$

\section{Gevolgtrekking}

Dit is vanuit die bogenoemde duidelik dat indien Rut 3:7 teen die agtergrond van Eksodus 4:25 gelees word, dit bepaald 'n nuwe lig kan werp op die gedeelte en hoe dit verstaan word, spesifiek met betrekking tot die verwysing na Rut wat Boas se 'voete' oopgemaak het en by hom gaan lê het. Dit is duidelik dat indien die gebruik van dié woord (רגל) in Rut 3:7 teen die agtergrond van Eksodus 4:25 geïnterpreteer word, dit spesifiek bydra tot die verstaan van die gedeelte binne die belangrikheid van die funksionering van die verbondsverhouding van die Here met Israel. Dit is verder duidelik dat beide Rut en Sippora die inisiatief neem en dat hulle ingrype lei tot die voortbestaan van 'n Judese familie wat van nasionale belang gaan wees. Laastens kan dit nie misgekyk word nie dat beide die gedeeltes daarop wys dat die vrouens van heidense oorsprong ook opgeneem is in die gemeenskap van Israel en dat hulle belangrike funksies in die heilsgeskiedenis van Israel vervul.

\section{Erkenning Mededingende belange}

Die outeurs verklaar dat hulle geen finansiële of persoonlike verbintenisse het met enige partye wat hul nadelig kon beïnvloed in die skryf van hierdie artikel nie.

\section{Outeursbydrae}

W.M. (Noordwes-Universiteit) was die projek leier en P.V. (Noordwes-Universiteit) was medeskrywer van die artikel.

\section{Literatuurverwysings}

Adam, A.K.M. (ed.), 2000, Handbook of postmodern Biblical interpretation, Chalice, St Louis.

Allen, L.C., Hartley, J.E. \& McKenna, J.E., [1982] 1996, Old Testament: The message, form, and background, 2nd edn., Eerdmans, Grand Rapids.

Beal, T.K., 1992, 'Ideology and intertextuality: Surplus of meaning and controlling the means of production', in D.N. Fewell (ed.), Reading between texts: Intertextuality and the Hebrew Bible, pp. 27-41, Westminster John Knox, Louisville.

Beal, T.K., 2000, 'Intertextuality', in A.K.M. Adam (ed.), Handbook of postmodern Biblical interpretation, pp. 128-130, Chalice, St Louis.

Berlin, A. \& Brettler, M.Z. (eds.), 2004, The Jewish study Bible, Oxford University Press, New York.

Blotz, J.W., 2005, 'Bitterness and friendship: A feminist exegesis of the book of Ruth', Theology and Mission 32(1), 47-54.

Boshoff, W.S., Scheffler, E. \& Spangenberg, I.J.J., 2000, Ancient Israelite literature in context, Protea Book House, Pretoria.

11.Volgens verskeie geleerdes is Rut geskryf as'n doelbewuste polemiese geskrif om te protesteer teen die streng en onverbiddelike maatreëls waarmee Esra en Nehemia in die na-eksiliese tyd teen gemengde huwelike opgetree het (kyk bv. Matthews 2004:210; Murphy 1981:86; Zenger 1986:25-28, 119-121, [1995] 2004:224-225; Spangenberg 2000:190; kyk ook Esra 9-10; Neh 10:30; 13:1-3, 23-29). Volgens Hepner (2005:44) kan die boek in die konteks as 'n 'polemic against exogamy' beskryf word.

12.Benewens Rut, die Moabitiese vrou, se rol in die heilsgeskiedenis van Israel, plaas die boek Rut ook klem op sogenaamde 'skaduvroue' (Levin 2010:70) se rol in die heilsgeskiedenis van Israel. Die geskrif benadruk dat die optrede van Tamar (vgl. $4: 12,18$ ) en moontlik ook dié van Lot se dogters (indien die dorsvloergebeure van 3:1-7 in die lig van Gen 19:31-38 geïnterpreteer word; vgl. bv. Sasson [1989] van 3:1-7 in die lig van Gen 19:31-38 geïnterpreteer word; vgl. bv. Sasson [1989]
1995:230-232; Yaron 2001:35-38, 44) deel uitmaak van die heilsgeskiedenis van 1995:230-232; Yaron 2001:35-38
Israel (Levin 2010:54-55, 70). 
Braulik, G., 1999, 'The book of Ruth as intra-Biblical critique on the Deuteronomic law', Acta Theologica 19(1), 1-20.

Brueggemann, W., 2003, An introduction to the Old Testament: The Canon and Christian imagination, Westminster John Knox, Louisville.

Bush, F.W., 1996, Ruth, Esther, Word Books, Dallas. (Word Biblical Commentary 9).

Campbell, E.F., 1975, Ruth: A new translation with introduction, notes, and commentary. Doubleday, New York. (The Anchor Bible 7).

Childs, B.S., [1974] 2004, The book of Exodus: A critical, theological commentary, Westminster John Knox, Louisville. (Old Testament Library).

Dommershausen, W., 1993, s.v., כנר, in Theological Dictionary of the Old Testament, Eerdmans, Grand Rapids, pp. 229-231.

Esses, M., 1977, Jesus in Exodus, Logos International, Plainfield.

Fewell, D.N. (ed.), 1992, Reading between texts: Intertextuality and the Hebrew Bible, Westminster John Knox, Louisville. (Literary Currents in Biblical Interpretation). PMCid:364086

Fischer, I., 1999, 'Apropos "Idylle" ... Das Buch Rut als exegetische Literatur', Bibel und Kirche 54, 107-112.

Gowan, D.E., 1994, Theology in Exodus: Biblical theology in the form of a commentary, Westminster John Knox, Louisville.

Hamlin, E.J., 1996, Surely there is a future: A commentary on the book of Ruth, Eerdmans, Grand Rapids.

Hepner, G., 2005, 'The separation between Abram and Lot reflects the Deuteronomic Law prohibiting Ammonites and Moabites', Zeitschrift für die Alttestamentliche Wissenschaft 117(1), 36-52. http://dx.doi.org/10.1515/zatw.2005.117.1.36

Holland, M. \& Steinhoff, V. (Hrsg.), 1995, Das Buch der Richter und das Buch Rut, R Brockhaus, Wuppertal. (Wuppertaler Studienbibel).

Hubbard, R.L., 1988, The book of Ruth, Eerdmans, Grand Rapids. (New International Commentary on the Old Testament).

Human, D.J., Van Rooy, H.F. Van Rensburg, F. \& Van der Watt, J.G., 2004, Die multivertaling Bybel, CUM, Vereeniging.

Krüger, P.A., 1984, 'The hem, the garment in marriage. The meaning of the symbolic gesture in Ruth 3:9 and Ezek 16:8', Journal of Northwest Semitic Languages XII, 79-86.

Krüger, P.A., 2004, 'Rut', in D.J. Human, H.F. van Rooy, F. van Rensburg \& J.G. van de Watt (reds.), Die multivertaling Bybel, ble 340-345, CUM, Vereeniging.

Kaiser, O., 1992, Grundriß der Einleitung in die kanonischen und deuterokanonischen Schriften des Alten Testaments, Mohn, Gütersloher. (Die erzählenden Werke; Bd 1).

LaCocque, A., 2004, Ruth: A continental commentary, transl. K.C. Hanson, Fortress, Minneapolis.

Lawrie, D., 1999, 'Narrative logic and legitimated interposing in the book of Ruth', Nederduits Gereformeerde Teologiese Tydskrif 40, 83-99.

Levin, M., 2010, Tamar and Ruth, Torah College, Jerusalem.

Linafelt, T. \& Beal, T.K., 1999, Ruth and Esther: Studies in Hebrew narrative \& poetry, Liturgical, Collegeville. (Berit Olam).

Linafelt, T., 1999, 'Ruth', in T. Linafelt \& T.K. Beal (eds.), Ruth and Esther: Studies in Hebrew narrative \& poetry, pp. xiii-86, Liturgical, Collegeville. (Berit Olam).

Loader, J.A., 1994, Ruth: Een praktische Bijbelverklaring, Kampen, Kok. (Tekst \& Toelichting)

Loader, J.A., 2004, 'A woman praised by women is better than a woman praised by seven men', HTS Teologiese Studies/Theological Studies 60(3), 687-701. http:// dx.doi.org/10.4102/hts.v60i3.610
Matthews, V.H., 2004, Judges and Ruth, Cambridge University Press, Cambridge. (The New Cambridge Bible Commentary).

Murphy, R.E., 1981, Wisdom literature: Job, Proverbs, Ruth, Canticles, Ecclesiastes, and Esther, Eerdmans, Grand Rapids. (The Forms of the Old Testament Literature XIII).

Newsom, C.A. \& Ringe, S.H. (eds.), [1992] 1998, Women's Bible commentary: With Apocrypha, expanded edn., Westminster John Knox, Louisville.

Nielsen, K., 1997, Ruth: A commentary, transl. E. Broadbridge, SCM, London. (Old Testament Library).

Nikaido, S., 2001, 'Hagar and Ishmael as literary figures: An intertextual study', Vetus Testamentum 51(2), 219-241. http://dx.doi.org/10.1163/156853301300102110

O’Donnell Setel, D., [1992] 1998, 'Exodus', in C.A. Newsom \& S.H. Ringe (eds.), Women's Bible commentary: With Apocrypha, expanded edn., pp. 30-39, Westminster John Knox, Louisville.

Pressler, C., 2002, Joshua, Judges and Ruth, Westminster John Knox, Louisville. (Westminster Bible Companion.) PMCid:1721395

Prinsloo, W.S., 1982, Die boek Rut, NG Kerkuitgewers, Kaapstad.

Roop, E.F., 2002, Ruth, Jonah, Esther, Herald, Scottdale. (Believers Church Bible Commentary). PMCid:126814

Sakenfeld, K.D., 2002, 'At the threshing floor: Sex, reader response, and a hermeneutic of survival', Old Testament Essays 15(1), 164-178.

Sasson, J.M., [1989] 1995, 'Ruth: A new translation with a philological commentary and a formalist-folklorist interpretation', Journal for the Study of the Old Testament 2. (The Biblical Seminar).

Sommer, B.D., 2004, 'Inner-biblical interpretation', in A. Berlin \& M.Z. Brettler (eds.) The Jewish study Bible, pp. 1829-1835, Oxford University Press, New York.

Spangenberg, I.J.J., 2000, 'The literature of the Persian Period (539-333 BCE)', in W.S Boshoff, E. Scheffler \& I.J.J. Spangenberg (eds.), Ancient Israelite literature in context, pp. 168-198, Protea Book House, Pretoria.

Steinhoff, V., 1995, 'Das Buch Rut', in M. Holland \& V. Steinhoff (eds.), Das Buch der Richter und das Buch Rut, pp. 239-315, Brockhaus, Wuppertal. (Wuppertaler Studienbibel).

Stendebach, F.J., 2004, s.v., רגל, in Theological Dictionary of the Old Testament, Eerdmans, Grand Rapids, pp. 314-315.

Stuart, D.K., 2006, The new American commentary: An exegetical and theological exposition of Holy Scripture, Broadman \& Holman, Nashville. (Exodus 2).

Thomas, N.J., 2002, 'Weaving the words: The book of Ruth as missiologically effective communication', Missiology XXX(2), 155-167.

Tigay, J.H., 2004, 'Exodus', in A. Berlin \& M.Z. Brettler (eds.), The Jewish study Bible, pp. 102-202, Oxford University Press, New York.

Vance, D.R., 2003, A Hebrew reader for Ruth, Hendrickson, Peabody.

Willis, J.T., 2010, Yahweh and Moses in conflict: The role of Exodus 4:24-26 in the book of Exodus, Peter Lang, Bern. (Bible in History 8).

Yaron, S., 2001, 'Sperm stealing: A moral crime by three of David's ancestresses', Bible Review 17(1), 35-38, 44.

Zenger, E., 1986, Das Buch Ruth, Theologischer Verlag, Zurich. (Zürcher Bibelkommentare 8).

Zenger, E. u.a. (Hrsg.), [1995] 2004, Einleitung in das Alte Testament, 3. Aufl., Kohlhammer, Stuttgart. (Kohlhammer Studienbücher Theologie; Bd 1/1).

Zenger, E., [1995] 2004, 'Das Buch Rut', in E. Zenger u.a. (Hrsg.), Einleitung in das Alte Testament, 3. Aufl., ble 222-229, Kohlhammer, Stuttgart. (Kohlhammer Studienbücher Theologie; Bd 1/1)

Zevit, Z., 2005, 'Dating Ruth: Legal, linguistic and historical observations', Zeitschrift für die Alttestamentliche Wissenschaft 117(4), 574-600. 